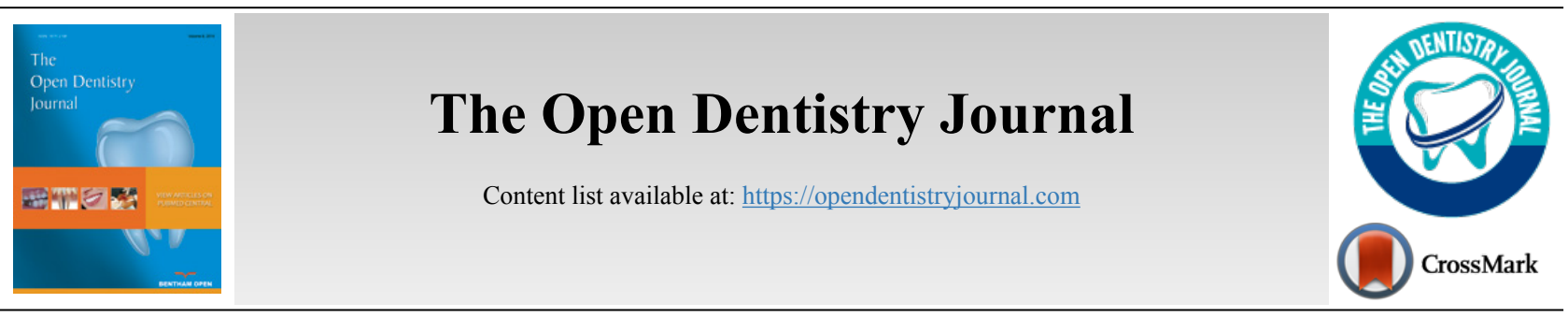

RESEARCH ARTICLE

\title{
Comparison of Shear Bond Strength of MIM Technology Brackets with Conventional and Rail-Shaped Mesh Bases: An In Vitro Study
}

Francisco Molina ${ }^{1}$, Karina Maria Salvatore Freitas ${ }^{2,3, *}$, Maria Cristina Rockenbach Binz Ordóñez ${ }^{4}$, Emerson Flamarion Cruz $^{5}$, Rafael Pinelli Henriques ${ }^{6}$ and Guillermo Mauricio Aguirre Balseca ${ }^{4}$

\author{
${ }^{1}$ Department of Orthodontics, FACOP, Bauru, SP, Brazil \\ ${ }^{2}$ Department of Orthodontics, Uninga University Center, Maringa, PR, Brazil \\ ${ }^{3}$ Department of Orthodontics, FACOP, Bauru, SP, Brazil \\ ${ }^{4}$ Facultad de Odontologia, Universidade dos Hemisférios, Quito, Ecuador \\ Department of Finance, FACOP, Bauru, SP, Brazil \\ ${ }^{6}$ Department of Foreign Student Care, FACOP, Bauru, SP, Brazil
}

\begin{abstract}
:
Objective:

The objective of this study was to evaluate in vitro the shear bond strength of two types of MIM (Metal Injection Molding) technology brackets, one with conventional mesh base and the other with rail-shaped mesh base.

Materials and Methods:

Forty human premolars received the bonding of 2 types of brackets: Group 1- 20 Synergy metal brackets (Rocky Mountain) with conventional mesh base and Group 2-20 H4 brackets (OrthoClassic) with rail-shaped mesh base. Both brackets were bonded with Resilience photopolymerizable resin (OrthoTechnology). The specimens were coupled to a Tinius Olsen universal test machine where the shear test was performed using a chisel. In addition, the amount of remaining resin in tooth crown with the ImageJ program was evaluated and the Adhesive Remnant Index (ARI). Intergroup comparison was performed by the independent $\mathrm{t}$ test and Chi-square test.

Results:

There was no statistically significant difference between the groups for any of the measures evaluated indicating that the mesh type of the brackets' base with MIM technology did not influence the shear bond strength of the brackets (shear bond strength, $p=0.191$; maximum load registered, $p=0.244)$. There was also no difference between the percentage $(p=0.602)$ and area of remaining resin in the teeth $(p=0.805)$ and IRA $(p=0.625)$ between the Synergy and H4 groups.

Conclusion:

Shear bond strength was similar in the two types of brackets with MIM technology evaluated. In addition, the remaining resin in the dental enamel of two types of brackets were also similar.
\end{abstract}

Keywords: Orthodontic, Bonding, Shear bond strength, Bracket, Conventional mesh base, Rail-shaped mesh base.

\begin{tabular}{l|l|l|r} 
Article History & Received: April 24, 2019 & Revised: June 11, 2019 & Accepted: July 15, 2019
\end{tabular}

\section{INTRODUCTION}

The process of bonding brackets and orthodontic accessories with resin composites on the dental enamel surface modified practice of specialty throughout the world, increasing

\footnotetext{
* Address correspondence to this author at the Department of Orthodontics, UNINGA University Center Rod PR 317, 6114 CEP 87035-510 Maringá-PRBrazil; Tel: 5514 991026446; E-mail: kmsf@uol.com.br
}

practicality of clinical procedures [1]. When the bracket is bonded directly to the enamel, the brackets are loosened accidentally, increasing the time and cost of orthodontic treatment and decreasing the possibility of obtaining the functionality and aesthetics that were outlined in the treatment plan [2]. Debonding of accessories is due to failures in the bonding technique, low retentivity of certain brackets and action of chewing forces [3]. 
In response to these adhesion problems, brackets with different meshes at their bases were used to obtain the desired adhesive effect, i.e., a strong and durable bonding. Among them, numerous meshes were used coupled to the bracket to give greater stability during the treatment and to provide stability so that the dental movements produced by the bracket have real and effective action [4].

The bases of the brackets have different configurations and designs, in order to impart greater integration of the adhesive system, thus increasing the mechanical retention. The orthodontic bracket must have an adhesive force sufficient to withstand masticatory forces and the activation of the mechanics used [5], the ideal adhesion force between enamel and bracket was previously described to be between 5.9 and 7.8 $\mathrm{MPa}$ [6]. Previous studies [6 - 8] in the literature have reported bond strength values between 2.8 and $10 \mathrm{MPa}$ to achieve sufficient adhesion for the orthodontic movement, minimizing brackets' debonding [9].

A previous systematic review of literature regarding invitro orthodontic shear bond strength testing found that many studies on in-vitro orthodontic bond strength fail to report test conditions that could significantly affect their outcomes [7]. Besides, water storage decreased bond strength on average by 10.7 MPa. Each second of photopolymerization time and each millimeter per minute of greater crosshead speed increased bond strength by 0.077 and $1.3 \mathrm{MPa}$, respectively [7].

Numerous forms of brackets were designed with their respective meshes to help achieve effective adhesion without neglecting an effective orthodontic technique. It is known that an effective adhesive will give greater stability to the adhered element. Likewise, numerous meshes attached to the base of the bracket were designed to give greater adhesion to the bracket. At first, the mesh was welded at the base of the bracket, showing good adhesion, but several times the mesh did not resist and loosened. In the 1980s, small pieces in a single block were designed that obtained good results with MIM (metal injection molding) technology.

The adhesion strength of the brackets with a laserstructured retention base appears to be significantly larger (twice as much) than single-mesh bond strength [10]. Fleishmann et al. [5], found that, although there were no significant differences between the evaluated brackets, the metallic bracket with laser retentions was the one with the highest mean adhesion force. Few studies have compared the bonding strength of various types of bracket bases.

Despite the use of brackets with MIM technology since its inception, adhesive effectiveness of conventional and railshaped mesh base brackets has not been studied. Therefore, the objective of this work was to compare, in vitro, shear bond strength of conventional and rail-shaped mesh base brackets, both developed with MIM technology.

Null-hypothesis tested that there is no difference between shear bond strength of conventional and rail-shaped mesh base brackets of MIM technology.

\section{MATERIALS AND METHODS}

This in vitro experimental study is based on shear bond strength measurements of brackets bonded to human premolars using a universal testing machine.

The sample size calculation was based on an alpha significance level of $5 \%(0.05)$ and a beta of $20 \%(0.20)$ to achieve $80 \%$ power of the test to detect a minimum difference of $1 \mathrm{MPa}$ with a standard deviation of 1.11 for shear bond strength [11]. Thus, sample size calculation showed a need for a sample of 20 specimens in each group.

Forty human premolar teeth were donated by educational institutions, teeth that were previously extracted due to orthodontic treatment.

Two types of brackets designed with MIM (Metal Injection Molding) technology were compared: One with a conventional mesh base and the other with a rail-shaped mesh base. Randomization was performed in division of the 40 premolars into 2 groups.

GROUP 1- 20 Synergy metal brackets of the Rocky Mountain brand (Synergy ${ }^{\circledR}$, Rocky Mountain Orthodontics, Denver, CO, USA), with conventional mesh base (Fig. 1).

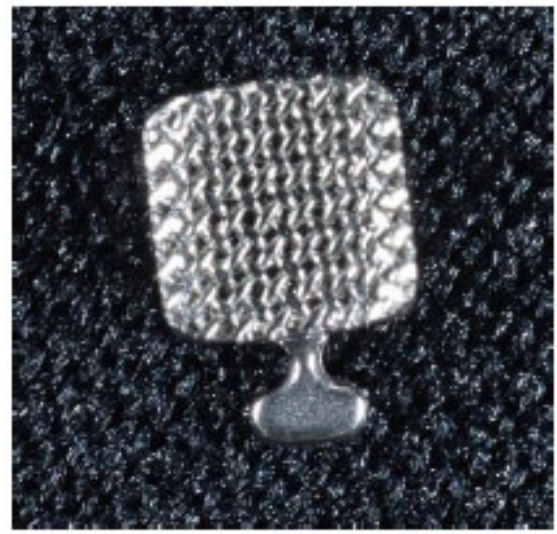

Fig. (1). Synergy bracket with conventional mesh base.

GROUP 2- 20 OrthoClassic H4 brackets (H4, OrthoClassic Orthodontics, USA), with rail-shaped mesh base (Fig. 2).

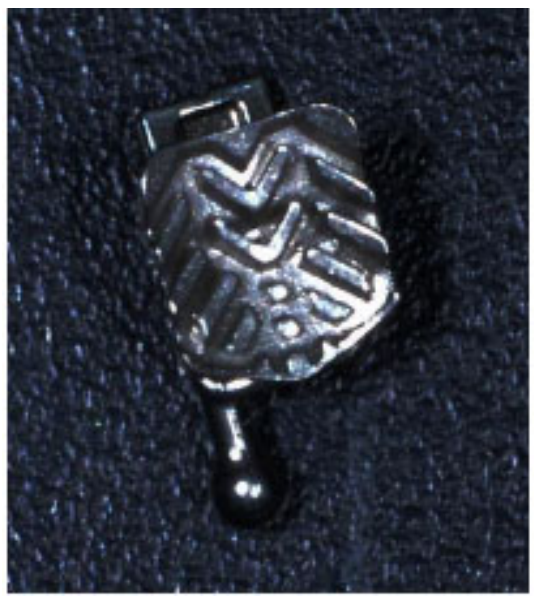

Fig. (2). H4 bracket with rail-shaped mesh base. 
40 human premolars were divided into 2 groups, 20 for group 1, Synergy, with conventional mesh base and 20 for $\mathrm{H} 4$ group, with rail-shaped mesh base. Teeth were fixed in cubes made with acrylic resin (Fig. 3), submerged till the cervical third of the crown of the tooth.

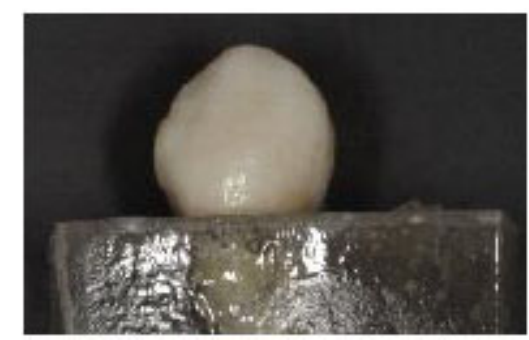

Fig. (3). Premolar fixed in an acrylic resin cube, submerged until the cervical third of the crown.

Prior prophylaxis with a pumice-type paste and a rotating brush was performed on the buccal surface of the crown of premolar, and then the enamel was air-dried and duly isolated. An attack with $37 \%$ phosphoric acid for 15 seconds was carried out gently, avoiding the friction in the tooth to prevent damaging enamel structures and reducing the adhesion surface.

Rinse for 15 seconds with a mixture of air and water, because if it is made with water only, acidic monomers can be left that can continue to demineralize enamel. Teeth were dried for five seconds with oil-free air to avoid contamination. The adhesive is then placed with microbrush in small applications without rubbing the tooth to avoid damaging the enamel prisms, and an air jet is directed to prevent a thick layer of adhesive.

Afterwards, a small amount of adhesive resin is placed in the base of each bracket with a metallic instrument and it is positioned on the vestibular face of the crown with slight pressure adjusting the correct positioning of the crown (Fig. 4). The adhesive system used for bonding all brackets was Resilience ${ }^{\circledR}$ Light-Cure Bracket Adhesive (OrthoTechnology, Lutz, FL, USA).

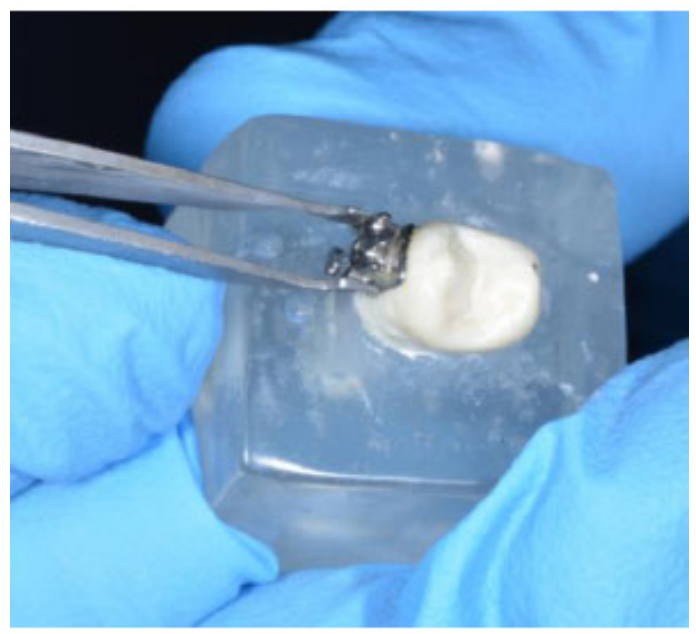

Fig. (4). Bracket bonding in buccal surface of the crown with slight pressure.
The resin is then photopolymerized by a $1800 \mathrm{mw} / \mathrm{cm}$ lamp for 10 seconds per mesial and 10 seconds per distal, giving a total of 20 seconds, as specified by the manufacturer of the adhesive system used.

The specimens were then coupled to a universal testing machine (Tinius Olsen Testing Machine, Model Super L-120, calibration certificate LabMetro, 2015) so that the shear strength of each bracket was tested with chisel (Fig. 5). The pressure exerted during the shear and even the release of the bracket was measured. The shear bond strength was measured in Megapascals (MPa) and the maximum load recorded was measured in Newtons $(\mathrm{N})$.

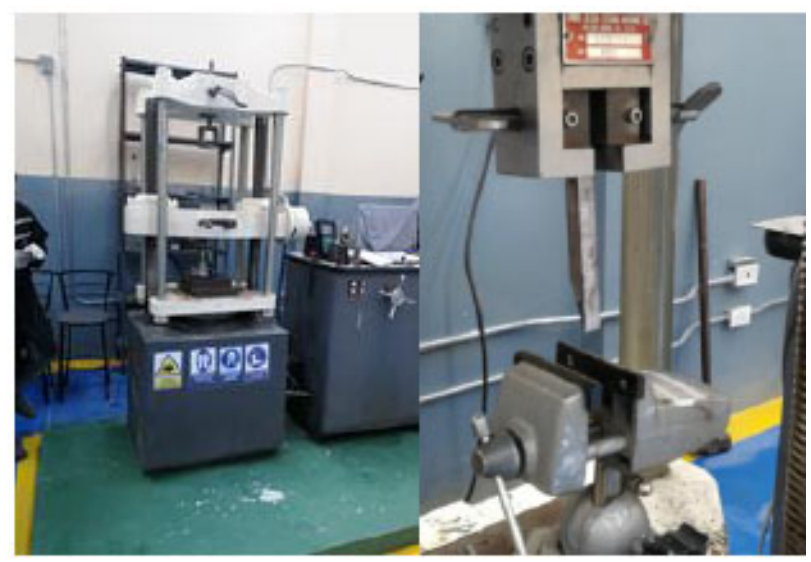

Fig. (5). Universal testing machine and appearance of the chisel used for shearing of the brackets.

In addition to the shear bond strength, the percentage of resin that remained adhered to the tooth after the experiment was evaluated, resulting in a value of the mesh type adhesiveness.

The evaluation was performed with the ImageJ program (version 1.51), which was developed by the Research Services Branch (RSB) of the National Institute of Mental Health (NIMH), part of the National Institutes of Health (NIH).

The measurement was made as follows: The surface area of each tooth was calculated, as well as the surface area of the remaining resin in the dental tissue, in pixels, dividing the two surfaces and multiplying by 100 results in the percentage of resin remaining (\%), which identifies the adhesion or lack of adhesion of different meshes (Fig. 6). The percentage is relative to the total area of the labial surface of the enamel, and is not related with the amount of resin placed and left on the tooth.

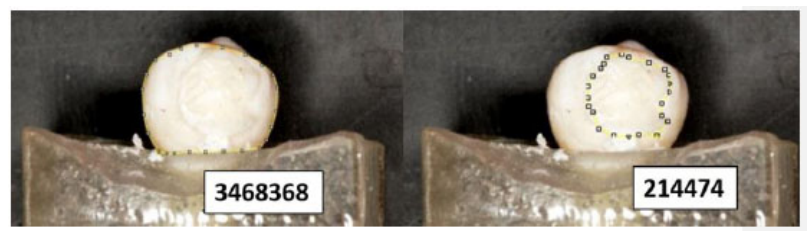

Fig. (6). Measurement of the total enamel surface area and the surface area of the remaining resin, in pixels, performed in the ImageJ program. 
Besides, the Adhesive Remnant Index (ARI) as described by Artun and Bergland [12] was also evaluated in each tooth, indicating the amount of adhesive left on the tooth after debonding. The scores vary from 0 to 3 :

Score 0 - No adhesive left on tooth

Score 1 - Less than half of the adhesive left

Score 2 - More than half left

Score 3 - All adhesive left on tooth with distinct impression of bracket mesh

\section{1.. Statistical Analysis}

The intra-examiner agreement was performed for the measurement of the area of remaining resin and the ARI. The ICCs were reported as 0.91 and 0.95 respectively, indicating excellent agreement.

Normality of the data was verified by the Shapiro-Wilk test, and since the data presented a normal distribution, parametric tests were used.

The comparison of the two groups of the shear bond strength measurements, the maximum registered load and the percentage and area of remaining resin were performed by the independent $t$ test.

The ARI was compared between the groups with a Chisquare test.

Statistical tests were performed with Statistica for Windows version 7.0 (Statsoft, Tulsa, Oklahoma, USA) and the significance level was set at $5 \%(P<0.05)$.

\section{RESULTS}

Table 1 shows the comparison between the groups of shear bond strength measurements (measured in Megapascals, MPa) and maximum load registered (measured in Newtons, N). There was no statistically significant difference between the groups for any of the measures evaluated (shear bond strength, $p=0.191$; maximum load registered, $p=0.244$ ), indicating that the mesh type of the brackets base with MIM technology did not influence the adhesive strength of the brackets.

Table 1. Results of intergroup comparison of shear bond strength and maximum load registered.

\begin{tabular}{|c|c|c|c|c|c|}
\hline \multirow[t]{2}{*}{ Variables } & \multicolumn{2}{|c|}{$\begin{array}{c}\text { GROUP 1 } \\
\text { SYNERGY } \\
\text { CONVENTIONAL } \\
\text { MESH } \\
\text { N=20 } \\
\end{array}$} & \multicolumn{2}{|c|}{$\begin{array}{c}\text { GROUP } 2 \\
\text { H4 } \\
\text { RAIL-SHAPED } \\
\text { MESH } \\
\mathbf{N}=\mathbf{2 0}\end{array}$} & \multirow[t]{2}{*}{$P$} \\
\hline & Mean & S.D. & Mean & S.D. & \\
\hline $\begin{array}{l}\text { Shear bond } \\
\text { strength } \\
\text { (MPa) }\end{array}$ & 9.58 & 5.80 & 11.83 & 6.24 & 0.191 \\
\hline $\begin{array}{c}\text { Maximum } \\
\text { load } \\
\text { registered (N) }\end{array}$ & 107.54 & 65.10 & 136.37 & 71.91 & 0.244 \\
\hline \multicolumn{6}{|c|}{$\begin{array}{l}\text { - Independent } \mathrm{t} \text { Test } \\
\text { S.D. - Standard Deviation } \\
P-\text { Statistical Significance }(P<0.05) \\
\text { MPa - MegaPascals } \\
\text { N - Newtons }\end{array}$} \\
\hline
\end{tabular}

Table 2 shows the comparison of the percentage and the area of remaining resin in the teeth between the two groups evaluated. There was no difference between the percentage $(p=0.602)$ and area of remaining resin $(p=0.805)$ in the teeth between the Synergy and H4 groups (Table 2). The percentage of resin remaining in the tooth is relative to the total area of the labial surface of the enamel, and not related to amount of resin placed and left on the tooth, so low percentages of resin remain (Table 2).

Table 2. Results of intergroup comparison of the percentage of remaining resin.

\begin{tabular}{|c|c|c|c|c|c|}
\hline \multirow[t]{2}{*}{ Variables } & \multicolumn{2}{|c|}{$\begin{array}{c}\text { GROUP 1 } \\
\text { SYNERGY } \\
\text { CONVENTIONAL } \\
\text { MESH } \\
\text { N=20 }\end{array}$} & \multicolumn{2}{|c|}{$\begin{array}{c}\text { GROUP } 2 \\
\text { H4 } \\
\text { RAIL-SHAPED } \\
\text { MESH } \\
\mathbf{N}=\mathbf{2 0}\end{array}$} & \multirow[t]{2}{*}{$P$} \\
\hline & Mean & S.D. & Mean & S.D. & \\
\hline $\begin{array}{c}\text { Percentage of } \\
\text { remaining } \\
\text { resin }(\%)\end{array}$ & 21.20 & 10.98 & 19.08 & 9.57 & $\begin{array}{c}0.602 \\
\mathrm{t}\end{array}$ \\
\hline $\begin{array}{c}\text { Area of } \\
\text { remaining } \\
\text { resin (pixels) }\end{array}$ & 64633.60 & 34229.04 & 61583.25 & 28160.46 & $\underset{\mathrm{t}}{0.805}$ \\
\hline
\end{tabular}

Table 3 demonstrates the comparison of the IRA scores between the groups. There was no difference in the IRA between the Synergy and H4 groups ( $p=0.625$, Table 3).

Table 3. Results of intergroup comparison of the ARI.

\begin{tabular}{|c|c|c|c|c|c|}
\hline $\begin{array}{c}\text { ARI Score } \\
\text { Group }\end{array}$ & $\mathbf{0}$ & $\mathbf{1}$ & $\mathbf{2}$ & $\mathbf{3}$ & Total \\
\hline $\begin{array}{c}\text { SYNERGY } \\
\text { CONVENTIONAL MESH }\end{array}$ & 0 & 4 & 8 & 8 & 20 \\
\hline $\begin{array}{c}\text { H4 } \\
\text { RAIL-SHAPED MESH }\end{array}$ & 1 & 6 & 7 & 6 & 20 \\
\hline Total & 1 & 10 & 15 & 14 & 40 \\
\hline $\mathbf{X}^{2}=\mathbf{1 . 7 5} \mathbf{D F}=\mathbf{3} \boldsymbol{P}=\mathbf{0 . 6 2 5}$ \\
$\begin{array}{l}\mathrm{X}^{2}-\text { Chi } i \text {-square Test Value } \\
P-\text { Statistical Significance }(P<0.05)\end{array}$
\end{tabular}

\section{DISCUSSION}

The results of the present study indicate that the shear bond strength was similar in the two types of MIM technology brackets evaluated (Table 1). Besides, the adhesive remnant in the tooth enamel also did not present a statistically significant difference between the groups (Tables $\mathbf{2}$ and $\mathbf{3}$ ).

The methodology of the present study obeyed standardization, the specimens tested were well adapted to the test machine used and allowed the work to be performed. Angulations and torques of the brackets were eliminated during bonding; the pressure was standardized during bracket positioning and bonding, so that the adhesive line had a thin and uniform thickness. In addition, adhesive excesses were removed without displacement of the bracket. For more legitimate comparisons between products, orthodontic adhesion 
strength tests should have a universal standardization $[5,13]$.

The average force transmitted to the bracket during chewing is around 40 to $120 \mathrm{~N}$, so it is desirable that a bracket has a tooth enamel adhesion strength greater than $120 \mathrm{~N}$ [14]. Reynolds [6] previously described that the ideal adhesion force between the enamel and the bracket is between 5.9 and 7.8 $\mathrm{MPa}$.

Wang et al. [15], performed a laboratory study and their mean strengths of adhesion ranged from 4.32 to $9.32 \mathrm{MPa}$ in tests performed on human teeth and six different bracket bases evaluated. Fleishman et al. [5], found a variation of the adhesion strength means between $3.81 \mathrm{MPa}$ (Edgewise Standard - Morelli) and 10.12 MPa (Discovery - Dentaurum). Fernandez et al. [11], found forces varying from 4.32 to 7.65 $\mathrm{MPa}$, in mesh and rail-shaped base brackets, bonded with conventional or self-etching adhesive.

In the present study, the mean adhesion strengths were 9.58 $\mathrm{MPa}$ for the conventional mesh Synergy bracket and $11.83 \mathrm{MPa}$ for the rail-shaped mesh $\mathrm{H} 4$ bracket (Table 1). These values are close to the higher values of the studies mentioned above [5, 15], indicating great adhesion of the two brackets evaluated to the dental enamel.

There was no statistically significant difference between the groups for shear strength, indicating that the mesh type of the bases of the brackets with MIM technology did not influence the adhesive strength of the same (Table 1).

The present study corroborates the results of the previous study by Fleishman et al. [5], who investigated the influence of various types of bracket base designs on the adhesion strength and there was no statistical difference between the brackets tested. The shear test included Discovery (Dentaurum) metallic with laser grooves; Monobloc (Morelli) - metallic one-piece with raised bumps; Edgewise Standard (Ortho Organizers) - metallic with MIM (Metal Injection Molding); Illusion Plus (Ortho Organizers) - ceramic with retention ridges; Composite (Morelli) - polycarbonate with raised bumps for mechanical retention; and Edgewise Standard (Morelli) metallic with single mesh. Although there were no significant differences between the evaluated brackets, the metallic Discovery bracket with laser retentions was the one with the highest mean adhesion force [5]. The Bracket Discovery presented higher adhesion strength in the study of Sorel et al. [10], comparing this bracket, which has laser retention, with a conventional mesh bracket.

Our results differ from the findings of Fernandez et al. [11], that found that mesh bracket bonded with self-etching primer presented greater adhesion than the rail-shaped base bracket bonded with conventional adhesive resin. Probably the greatest difference of the study of Fernandez et al. [11], are in the different types of resin used and not in the types of bracket bases tests; in addition, the type of resin used was different from that used in the present study, which may justify the differences, and numerically, our values of shear bond strength were higher than that of Fernandez et al. [11].

Wang et al. [15], evaluated different brackets with different bases, with single and double meshes of different sizes, and found that, among mesh brackets, Dentaurum, with larger mesh size, produced higher bond strength than brackets with smaller meshes. The two brackets studied in the present study had different meshes, and the bracket with grooved mesh had a larger mesh size; however, we found no difference in shear bond strength between the larger and smaller meshes.

The results of the evaluation of the amount of resin remaining in the dental enamel showed a percentage of $21.20 \%$ in the Synergy bracket and 19.08 in the H4 bracket, it showed that there was no significant difference in the percentage and the area of resin remaining in the teeth between the groups Synergy and H4 (Table 2). Park et al. [16], also found no differences in the adhesive remaining index evaluating 3 types of brackets.

In the present study, the area and percentage of remaining resin and the Adhesive Remnant Index (ARI) were used as described by Artun and Bergland [12]. This ARI classification evaluates the amount of resin adhered to the tooth, after removal of the bracket, and suggests several degrees of susceptibility to enamel fracture. The ideal is to achieve high scores on the ARI (greater amount of material adhered to the tooth) to maintain the integrity of the enamel [17].

In the present study, most teeth showed ARI scores of 3 and 4, by the ARI [12], for both groups studied (Table 3). In the study by Fleishmann et al. [5], for the bracket with MIM technology, half showed score 3 , and the other half, scores 2 and 3, similar to the results of our study.

The presence of resin remnant in the tooth is dangerous, as there is a greater chance of cohesive fractures occurring in the enamel, since it indicates that the predominant fracture interface was adhesive/enamel [5]. The most favorable fracture interface for safe removal is the bracket/adhesive, with retention of the adhesive material on the enamel surface, as this demonstrates that the cohesive strength of the enamel was superior than the adhesion strength of the base of bracket to the adhesive [5]. This way, the occurrence of enamel fractures becomes practically non-existent, and removal of the residual adhesive is carried out with the aid of special burs, which do not damage dental tissue.

The removal of resinous adhesive after brackets' debonding is still an issue of interest. The amount of remnant adhesive left on the enamel can be controlled by altering the adhesive-bracket interface characteristics to enhance the interface strength by varying the filler content and bracket base retentive characteristics [18].

Therefore, for adhesion of orthodontic accessories to dental enamel, the most important is the strength of the resin and its bonding properties and adhesion to the enamel. The mesh bases evaluated are important, but do not overlap the importance of shear bond strength of the resinous adhesive material.

It seems that the type of the mesh in the bracket base did not influence the shear bond strength of the brackets to the dental enamel. It seems that the force of adhesion is related to other factors such as the type of adhesive material used [11, 19], the curvature and size of the bracket base $[16,20]$, the quality of the dental enamel, among other factors. 


\section{CONCLUSION}

The null-hypothesis tested was accepted. The shear bond strength was similar in the two types of MIM technology brackets evaluated. In addition, the remaining resin in the dental enamel of the two types of brackets was also similar.

\section{ETHICS APPROVAL AND CONSENT TO PARTI- CIPATE}

Not applicable.

\section{HUMAN AND ANIMAL RIGHTS}

No Animals/Humans were used for studies that are base of this research.

\section{CONSENT FOR PUBLICATION}

Not applicable.

\section{STANDARDS OF REPORTING}

It was an in-vitro experimental study. No ethical methodology was needed.

\section{AVAILABILITY OF DATA AND MATERIALS}

The data sets analyzed during the current study are available from the corresponding author on request.

\section{FUNDING}

None.

\section{CONFLICT OF INTEREST}

The authors declare no conflict of interest, financial or otherwise.

\section{ACKNOWLEDGEMENTS}

Declared none.

\section{REFERENCES}

[1] Chevitarese O, Ruellas ACO. Braquetes Ortodônticos como utilizá-los. São Paulo: Editora Santos 2005.

[2] Klocke A, Shi J, Vaziri F, Kahl-Nieke B, Bismayer U, Effect of time on bond strength in indirect bonding. Angle Orthod 2004; 74(2): 245-50.

[PMID: 15132452]

[3] Pinto AS, Pinto LAMS, Cilense M, Melo ACM, Terra AMV. A reciclagem de braquetes na clínica ortodôntica. Ortodontia 1996; 29: 63-7.

[4] Fleming PS, Johal A. Self-ligating brackets in orthodontics. A systematic review. Angle Orthod 2010; 80(3): 575-84. [http://dx.doi.org/10.2319/081009-454.1] [PMID: 20050755]

[5] Fleishmann LA, Sobral MC, Santos GC Junior, Habib F. Estudo comparativo de seis tipos de braquetes ortodônticos quanto à força de adesão. Rev Dent Press Ortodon Ortop Facial 2008; 13: 107-16. [http://dx.doi.org/10.1590/S1415-54192008000400013]

[6] Reynolds IR. A Review of Direct Orthodontic Bonding. Br J Orthod $1975 ; 2: 171-8$.

[http://dx.doi.org/10.1080/0301228X.1975.11743666]

[7] Finnema KJ, Ozcan M, Post WJ, Ren Y, Dijkstra PU. In-vitro orthodontic bond strength testing: A systematic review and metaanalysis. Am J Orthod Dentofacial Orthop 2010; 137: 615-22 e3.

[8] Pickett KL, Sadowsky PL, Jacobson A, Lacefield W. Orthodontic in vivo bond strength: comparison with in vitro results. Angle Orthod 2001; 71(2): 141-8

[PMID: 11302591]

[9] Di Guida LA, Benetti P, Corazza PH, Della Bona A. The critical bond strength of orthodontic brackets bonded to dental glass-ceramics. Clin Oral Investig 2019; 23(12): 4345-53

[http://dx.doi.org/10.1007/s00784-019-02881-5] [PMID: 30953165]

[10] Sorel O, El Alam R, Chagneau F, Cathelineau G. Comparison of bond strength between simple foil mesh and laser-structured base retention brackets. Am J Orthod Dentofacial Orthop 2002; 122(3): 260-6. [http://dx.doi.org/10.1067/mod.2002.125834] [PMID: 12226606]

[11] Fernandez SL, Calero JMP, Ibarra JG, Lozano MB, Pérez HE. Fuerza de retención al esmalte con adhesivos usados en ortodoncia, utilizando dos tipos de base de brackets (estudio comparativo in vitro). Rev Odontol Mex 2004; 8: 122-6.

[12] Artun J, Bergland S. Clinical trials with crystal growth conditioning as an alternative to acid-etch enamel pretreatment. Am J Orthod 1984; 85(4): 333-40.

[http://dx.doi.org/10.1016/0002-9416(84)90190-8] [PMID: 6231863]

[13] Littlewood SJ, Redhead A. Use of jigs to standardise orthodontic bond testing. J Dent 1998; 26(5-6): 539-45.

[http://dx.doi.org/10.1016/S0300-5712(98)00016-5] [PMID: 9699449]

[14] Eliades T, Brantley WA. The inappropriateness of conventional orthodontic bond strength assessment protocols. Eur J Orthod 2000; 22(1): 13-23.

[http://dx.doi.org/10.1093/ejo/22.1.13] [PMID: 10721241]

[15] Wang WN, Li CH, Chou TH, Wang DD, Lin LH, Lin CT. Bond strength of various bracket base designs. Am J Orthod Dentofacial Orthop 2004; 125(1): 65-70.

[http://dx.doi.org/10.1016/j.ajodo.2003.01.003] [PMID: 14718881]

[16] Park DM, Romano FL, Santos-Pinto A, Martins LP, Nouer DF. Análise da qualidade de adesão de diferentes bases de braquetes metálicos. Rev Dent Press Ortodon Ortop Facial 2005; 10: 88-93. [http://dx.doi.org/10.1590/S1415-54192005000100010]

[17] Neves MG, Brandão GA, de Almeida HA, Brandão AM, de Azevedo DR. In vitro analysis of shear bond strength and adhesive remnant index comparing light curing and self-curing composites. Dental Press J Orthod 2013; 18(3): 124-9.

[http://dx.doi.org/10.1590/S2176-94512013000300020] [PMID: 24094022]

[18] Eliades T, Brantley WA. Orthodontic Applications of Biomaterials - A clinical guide Sawston. Cambridge: Woodhead Publishing 2017.

[19] Bishara SE, Gordan VV, VonWald L, Jakobsen JR. Shear bond strength of composite, glass ionomer, and acidic primer adhesive systems. Am J Orthod Dentofacial Orthop 1999; 115(1): 24-8. [http://dx.doi.org/10.1016/S0889-5406(99)70312-4] [PMID: 9878954]

[20] Floriano H, Mori AT, Maltagliati AMA, Lino AP. Estudos da resistência à tração de braquetes metálicos colados em relação a alguns tipos de base. Rev Paul Odontol 2001; 23: 20-3. 